\title{
It takes a community to build a framework: Information literacy within intercultural settings
}

\author{
Journal of Information Science \\ $1-10$ \\ (c) The Author(s) 2016 \\ Reprints and permissions: \\ sagepub.co.uk/journalsPermissions \\ nav \\ DOI: $10.1177 / 0165551510000000$ \\ jis.sagepub.com
}

@SAGE

\author{
Alison Hicks \\ School of Information Studies, Charles Sturt University, Australia
}

\author{
Annemaree Lloyd \\ Swedish School of Library and Information Science, University of Boras, Sweden; Adjunct Professor, School of Information Studies, \\ Charles Sturt University, Australia
}

\begin{abstract}
Information literacy practice plays a key role in the transitional processes of individuals within new intercultural settings. While this ability to adjust to new cultural contexts is increasingly important within today's multicultural societies, campuses and workplaces, typical approaches to information literacy education struggle to scaffold the newcomer's disrupted information landscapes. In focusing on prescriptive skills, information literacy standards position linguistic and cultural difference as a learning deficiency. Yet, when alternative information literacy frameworks centre upon personal habits of mind, they fail to account for contextual dynamics. In this conceptual paper, the authors use research into the health practices of resettling refugees as an example to argue that a move away from behaviourist approaches to information literacy refocuses our attention on questions of adjustment and engagement with cultural understandings of information, and forms a more inclusive way to consider the diversity of today's information societies.
\end{abstract}

\section{Keywords}

Information literacy; Intercultural; Information practices; Refugee; Health

\section{Introduction}

The ability to adjust to new cultural contexts is increasingly important in today's multicultural societies. Whether an individual engages in travel as a student or merely starts to experience a more diverse home society or workplace, he or she faces a disrupted information environment where people and systems appear to work in seemingly erratic ways. In this situation, habitual information practices may not work, and familiar support structures may not be available. Instead, the individual is forced to develop a series of adaptive information literacy practices in order to adjust to new cultural norms and realities. However, while the development of information literacy, which is defined in this study as a "way of knowing the many environments that constitute an individual's being in the world" [1, p.26] is seen to bridge and facilitate this time of change, information literacy education neither focuses on nor affords the strategies that are necessary to scaffold and support the transition through uncertainty. Whether information literacy is framed by behaviourist standards, such as the Association of College and Research Libraries (ACRL) Information Literacy Competency Standards for Higher Education [2], or a constructivist framework, such as ACRL's new Information Literacy Framework for Higher Education [3], the failure to engage with scholarship that positions information literacy as a complex social practice $[4,5,6]$ means that librarians and scholars are unable to account for both the diversity and the demands of today's dynamic, information societies. In turn, this limits research and fails to address the information literacy mandate of lifelong learning.

Taking a thematic approach, this conceptual paper considers the emergence of information literacy within intercultural settings, which are defined as contexts where individuals from different cultures interact [7]. The first half of the paper explores how research into information literacy within intercultural settings has been characterised to date. 
Focusing on reviewing core Library and Information Science (LIS), Education and dissertation or thesis databases in English, French and Spanish for studies that explore both academic and everyday information experiences in intercultural contexts, research in this area has predominantly centred on international students and can generally be characterised as being framed through either a behaviourist or a constructivist approach to information literacy. In the second half of the paper, the authors, who take a sociocultural perspective to information literacy, will then use research into the information literacy practices of resettling refugees as an example to argue that a sociocultural approach to information literacy forms a more inclusive way to consider the diversity of today's information societies. The paper will finish by reflecting on the implications of this scholarship in light of ACRL's recent filing of a new Information Literacy framework, before highlighting a number of potential future areas of research and exploration that emerge from this approach. While acknowledging that the related field of information behaviour has explored sociocultural approaches to information experiences within intercultural settings, the authors' emphasis on learning means that this paper will focus on exploring information literacy research.

\section{Behaviourist approaches to information literacy within intercultural settings}

Like the majority of information literacy research, studies of intercultural contexts have consistently been structured by national competency standards, such as ACRL's Information Literacy Competency Standards for Higher Education [2], as well as the Association of American Colleges and Universities (AACU)'s VALUE rubric [8] and the Australian and New Zealand Information Literacy Framework (ANZIL) [9]. Focused on academic settings and centred upon the measurement of changes in user behaviour against expert models [10], these studies position information literacy as either a series of steps to be followed [11] or as a set of personal attributes [12]. Characterised as essentially behaviourist in nature [13], these studies have helped to legitimise and popularise interest in information literacy [6, p.331]. However, the emphasis on the individual's acquisition of generic information skills means that the behaviourist approach can be seen to rest upon and cause a number of problematic assumptions within intercultural settings, including the unacknowledged imposition of a culturally specific model of information literacy, the misrepresentation of the nature and purpose of international education and a deficit approach to individual learning.

The most common way that information literacy has been addressed within intercultural settings is through the translation of information literacy standards into the second language [e.g. 14, 15, 16, 17] or the global classroom [e.g. $18,19]$. Framed as the acquisition of either strategic and transferable library research skills [15] or knowledge of key resources in the field $[16,17]$, these studies draw from the idea that information literacy standards are rational or objective and that information literacy itself forms a set of generic and universal competencies that are applicable within and transferable to any setting. Recognising that librarians may be forced to teach to these professionally endorsed standards, the assumption that information literacy skills can be "taught, evaluated, and measured independently of the practical tasks and contexts in which they are used" [6, p.330] raises a number of problematic issues within intercultural settings. On the one hand, the understanding that information literacy is identical within all settings can be critiqued for trivialising and reducing the complexity of information activity within disciplinary contexts. On the other hand, the idea that information literacy is neutral or value-free is particularly troublesome because it fails to recognise that these ideas structure student learning through a culturally specific frame of reference. The 1989 ACRL Standards, for example, which are promoted as "common to all disciplines, to all learning environments, and to all levels of education" are not neutral [2]. Instead, they constitute a "eurocentric, socially and culturally constructed set of skills" [20, p.19] that emerges from a tradition of Western positivism and economic-rationalist ideas of literacy or ways of knowing [1, p.83]. A failure to recognise or to acknowledge the cultural and ideological assumptions that underpin these conceptual understandings of information literacy has a number of implications for our understandings about both the purpose and the way that librarians teach information literacy.

One of the most important implications of this autonomous or technical model of information literacy [21] is on our understanding about the nature and the purpose of information literacy within intercultural contexts. Most simply, when information literacy is seen to form a single way of knowing [20, p.39], we limit our understandings about the nature of information literacy by marginalising other forms of knowledge that support literate practice, such as the cultural and social practices that students bring with them to a classroom. At the same time, when this culturally specific model of information literacy is positioned as both standard and as autonomously having a positive effect on an individual [21, p.77], the purpose of education is presented as a one-way or unilateral process of assimilation to Western values [22, p.243]. These ideas, which appear to be driven by a belief about the inferiority of non-Western education, position standards based information literacy as remedial, or as a way for students to "rectify some aspect of a deficit that they have as a result of being from another culture" [24, p.456]. They are also particularly problematic given the emphasis 
within higher education on internationalisation and the "decolonisation of education" [23,p.20], the celebration of diversity within educational mission statements $[25, \mathrm{p} .8]$ as well as the ideas of liberal pluralism and democracy that characterise many societies today [26]. There is a further risk that ideas such as these position Western values as a mechanism for upward mobility [27] and information literacy as an imperial project [28].

Another important implication of this conception of information literacy relates to our understanding of individual behaviour within these new intercultural contexts. The focus on measurement that is inherent within behaviourist research often leads to an assessment of individual actions (and actors) within new settings, particularly within studies of international and ethnic minority students. Yet, when information literacy is presented as universal, students who are not seen to possess these 'common' skills are seen to be unprepared or deficient. Thus, international students are marked as possessing inappropriate skill sets [30, p.210], while their abilities "lag behind those of US students" [29, p.1]. These ideas are particularly troublesome because they position students as empty vessels who need to internalise the information skills that they are perceived to be lacking. At the same time, the focus on the individual within the behaviourist approach to information literacy means that it is personal inadequacies or ethnocentric character flaws that are seen to be the reason why students do not already possess these competencies. International students are thereby found to have "special difficulties" [31, p.271] or to demonstrate an "obvious lack of self-sufficiency" [32, p.129]. Their nationality or ethnicity may even be interpreted as a barrier to learning with cultural difference likely to "adversely affect international students' ability to develop information literacy skills" [33, p.223]. These inferences silence different perspectives by positioning linguistic and cultural variance as both a learning deficiency as well as deviance from the norm. They also lead to the creation of essentialist stereotypes and biased instruction models [34] as overgeneralisations make it hard to see adjustment to new settings within the broader context of all students' adaptation to higher education [22, p.252].

\section{Constructivist approaches to information literacy within intercultural settings}

A less common way that has been used to frame information literacy within intercultural settings is through the lens of constructivism, an approach that developed in direct contrast to the perceived limitations of these functional or technical visions of information literacy [35, p.30]. Drawing from the idea that learning centres upon knowledge construction rather than in response to a stimulus, a constructivist approach moves the focus of research from actual behaviour to the user's understanding of their behaviour [35, p.22] and positions information literacy as a learning process or as a habit of mind [36]. Most commonly seen within Australian studies, this approach may also start to become more common in the United States as librarians and researchers begin to explore ACRL's new Information Literacy Framework for Higher Education [3]. Filed in February 2015, and emerging from a recognition of the need to move beyond the prescriptive and "mechanistic bureaucracy of standards-based education" [37], the Framework emerged from a librarian-focused Delphi Study and is based on theories of metaliteracy and threshold concepts, as well as the idea that learning has a number of affective and attitudinal dimensions. These ideas, which reflect a number of the key ideas within the United Kingdom's Seven Pillars of Information Literacy [38] and A New Curriculum for Information Literacy [39], position the Framework as a constructivist approach to information literacy.

Like studies that are framed by information literacy standards, constructivist research into intercultural settings has consistently focused on international and English as a Foreign/Second Language students [e.g. 40, 41, 42, 43, 44, 45, 46]. While constructivist and behaviourist approaches to information literacy assume that it is the individual mind that is at the centre of knowledge creation [47, p.83], the emphasis on exploring experience rather than measuring behaviours means that constructivist research tends to focus on the individual in relation to the setting, or the student's relationship with the environment rather than on expert judgment. This means that within an intercultural setting, linguistic and cultural variables are seen to bring complexity rather than deficiency to international student information literacy experiences [48, p.2], and that difference is not positioned as a personal failing [45, p.142]. Instead, researchers recognise that students develop a wide range of creative and adaptive strategies to work around unfamiliarity, for example using a search engine to find synonyms [45] or to establish an author's gender [42]. Coupled with the understanding that common issues with typing errors or lengthy lists of results are not unique to international students, Hughes and Bruce conclude that difference should be positioned as being related to "the degree of difficulty [rather than] the nature of the difficulty itself" [49, p.38]. These observations create a more inclusive approach to information literacy while also re-focusing our attention on "what constitutes information in different settings or contexts, in different disciplines, professions, cultures and communities" [50, p.193].

Nonetheless, while this approach has started to represent the diversity within information literacy, the constructivist underpinnings of this research into intercultural settings mean that studies remain focused on both individual processes 
and decontextualised settings. This means that neither the subject, nor the "contexts of information seeking are considered to be of particular importance" [35, p.24], an idea that is particularly problematic within intercultural settings. For a start, this neglects both the student's positioning within a setting as well as the active dynamics of a situation, for example "the multidimensional tension and conflict students experience in a transnational situation" [51, p.457]. The failure to account for the realities of local practice may also lead to naive assumptions that do not take existing social relations into account [26, p.204], for example, claims that information literacy facilitates effective or empowering use of technology within intercultural settings [50].

More specifically, however, in neglecting the sociocultural practices that characterise and situate our knowing of a context, constructivist approaches to information literacy can be critiqued for separating information literacy from the very meanings and values through which it is constituted and legitimised. The Framework, for example, has been critiqued for perpetuating or reinforcing the idea that information literacy emerges from a unified body of knowledge and unchanging beliefs [52] or is an autonomous entity that exists untouched by broader social influences [53]. In turn, these ideas may further serve to normalise or embed dominant narratives and culturally specific ideas within our understanding of information literacy as the threshold concept architects Meyer and Land acknowledge [54, p.13], and as Morgan claims has already occurred with the inclusion of the pragmatic and capitalist centred idea of information value within the Framework [53, p.189]. Thus, while constructivist understandings of information literacy shy away from idealising an exemplary student, as tends to happen within standards based education, the failure to engage with broader contexts and settings can be seen to idealise information literacy itself, an understanding that is equally troublesome [53].

\section{Sociocultural approaches to information literacy and intercultural settings:}

A sociocultural or constructionist lens forms the least common approach to information literacy within intercultural settings but, in positioning information literacy as a practice that draws from context for its shape and prefigurement and from social interaction for its emergence, it is perhaps the one with the most potential for facilitating a holistic understanding of newcomer experiences. Represented by a wider range of theories and characterised by "the information relationship that is created when people participate and interact with people and tools in their information environment" [1, p.29], the sociocultural approach can thereby be seen to extend constructivist thinking by acknowledging the collectiveness of knowledge creation as well as the dynamic nature of interaction, language and social practice. This means that from a sociocultural perspective, information literacy is understood to emerge from a community's collective understanding of competent practice [55, p.xii] and to be enacted in relation to the legitimised and sanctioned values, the information modalities and the social, economic and political elements that shape a social setting $[6,56]$. In turn, the shift from individual agency to situated and social practices $[1,55]$ entwines information practices into the context. In taking a broader view of the socio-cultural influences that shape information literacy, the majority of information literacy researchers who subscribe to this approach draw from socio-cultural theories of learning and the new literacies movement [57] or employ a social practice [58] or a critical theory lens [59]. This attunes both researchers and practitioners to the social and material resources that make the practice visible and is particularly useful when dealing with groups or individuals who may not share the same cultural or linguistic traditions.

In focusing our attention towards how information literacy emerges and is shaped within a new social context, the use of a sociocultural lens opens researchers to a reframing about the nature, emergence and scope of the information literacy experience, rather than focusing on the implementation of a universal set of skills. These ideas build upon UNESCO's definition of information literacy which, while focused on cultural issues, takes a more instrumental approach to learning [60]. When applied to intercultural settings, sociocultural research thereby suggests that information literacy is fractured, and established knowledge bases or ways of knowing are disrupted by the circumstances of uncontrolled displacement (in the case of refugees) or even controlled transition (in the case of migrants) $[61,62,63]$. In other words, information literacy cannot just be considered an academic skill; as the experiences of refugees demonstrates, the need to reengage with information and to establish or shape the information landscape is critical to successful resettlement because it helps each individual to reorient, adjust and reframe new understandings $[62,63]$. Research further demonstrates that the development of information literacy within a new environment is not a decontextualised, individual process. Instead, it requires that newcomers develop an understanding of how the information landscapes of their new environments are organised and connected as well as how access to information and knowledge sites are operationalised. This may require a change in established or routine social activities to engage with the practice, for example seeking information from outside the family (rather than from within), or locating and using sources that are not familiar, for instance, using online instead of analogue sources. 
Transition into a new environment may be further complicated when language, literacy and comprehension skills are poor. These ideas will be further explored by using previous refugee health information practice research [63] from one of the authors (Lloyd) as an example of the sociocultural approach to information literacy within intercultural contexts. Findings from this study, where the sociocultural approach was applied to understand how refugees connect with the health information environment of their adopted country and develop the information practice that facilitates resilience in the face of health related uncertainty, demonstrated that participants addressed these challenges creatively and together, which further highlights the role of information literacy from a collective perspective.

\subsection{Example Refugee Health Literacy Study:}

The methodology for this qualitative study has previously been described in detail [63]. Briefly, the sample comprised of 20 participants mainly of African background, which is in itself diverse, with no clear language or cultural group being represented in the sample. The majority of participants originated from the Sudan, Rwanda, Congo and Uganda. The study investigated how resettling refugees experience a new health environment and develop health literacy practice. Face-to-face interviews were conducted and the data was transcribed and analysed using a constructivist grounded theory method [64] to identify key themes.

An important finding of this study centres upon collective coping and the role of people and groups as a resource for information and as a source of information, particularly when literacy or language skills are limited. This leads to the suggestion that health information is experienced through others who take on the role of formal, informal or contingent intermediaries. Engaging with non-textual sources of information was critical to the resilience building that is necessary for successful transition [63]. Participants identified other people as critical for:

- Instructional reasons - e.g. to provide information about how to do something (such as accessing health services). This experience occurred through everyday settings;

- Mediation reasons- to assist newcomers develop their understanding of the nuances of their new landscapes;

- Confirmatory reasons- to confirm that information or understanding was correct; and,

- Local reasons- to interpret the content and local knowledges associated with living in a specific setting [63, p.59].

\subsection{Dealing with disruption: Collective coping and the activity of pooling}

The health literacy study highlighted the significance of connecting with other people in similar circumstances to create social networks that strengthen the ability to cope. This is particularly important when knowledge bases have become fragmented through relocation. Collective coping builds resilience and draws from a process of "engaging with others in meaningful, purposeful and culturally congruent ways" [65, p.4]. In this study, collective coping emerged as a joint activity where refugees who are faced with a health issue, and who possess limited knowledge of the new health environment worked together to pool fragmented information and combine limited literacies (information, digital and functional literacies) and skills to locate information in order to reduce uncertainty [63]. Participants described how they collectively formed a layperson understanding of a health diagnosis and treatment options by pooling information and ways of knowing. Working together allowed minimal resources to be drawn upon and enabled participants to develop rudimentary understanding of the formal and established knowledges that shape the health landscape at both a system level and at everyday levels where the information landscapes reflects collective knowledge that reference nuanced and local ways of knowing.

Pooling represented a strategic information activity for decision-making and provided a basis for initiating or furthering informed discussions with the medical profession. A participant describes a common process that would occur before they go to the doctor or sometimes even determine whether to seek medical advice [63, p.61]

We talk about it first and then we go to the Internet, one person does this. And as we are talking about it, someone is checking. We check what we know and what is available.

As a strategic activity, pooling allowed segments or incomplete bits of information to be incorporated into shared knowledge, acting as a catalyst for problem solving. The activity was closely associated with trust and often occurred in everyday spaces and within community sites or family groups. Faith-based groups were often reported as an everyday space where collective coping and pooling information occurred, particularly over health related issues. 
Sometimes we would meet after church is over... and they give me advice

Pooling information occurs for a number of reasons, such as when different treatment options are too expensive and individuals have to find alternative solutions, or when it was perceived that the treatment option is not working and that another solution was required. One participant described pooling of information as creating a 'Plan B'. Another provided a description of pooling, whereby friends and family met to work out a solution to a medical issue. During this gathering, stories were shared about other people with similar ailments, the use of traditional treatments and using the Internet to find secondary sources. In describing the role of the community:

The community there is very, very important; especially let me say that the neighbours were important in concern of treatment and advice. They are really important. If you had a problem in your family they are the ones solving it. They are able to bring everything to one basket

Analytically, pooling occurred on two levels. At one level, pooling related to understanding where information was located and how to access it. Working together to piece together information, participants were able to identify the types of information they required, for example, where to get cheaper medicines or information that explains symptoms; and, where to locate sources of information from within the system, for instance, from the Internet, from medical shows on the television, from the doctor or from a pamphlet. On a second level, pooling related to content and comprehension. On this level, participants contributed and combined their content knowledge about the issue at hand. Pooling acted to alleviate the stress created by knowledge disruptions and to solve particular problems that their transition caused. However, participants reported that difficulty in piecing information together, comprehending the information, and understanding the meaning or consequence was often experienced as uncertainty, or what was described as 'knowing what is true'. This common sentiment references a second issue which highlights the creation of mis-information that may occur when information gathering strategies and comprehension of information are piecemeal, and small segments of information are drawn together randomly from a wide range of sources without a cohesive information literacy strategy being practised [63].

The results from this study further highlight that entering a new information landscape to access information is complex and fraught with risk of mis-information on multiple levels. This suggests that the ability to collectively cope and develop resilience in times of uncertainty relies upon newcomers developing the capacity to recognise what information counts and upon communities sharing knowledge about ways of entering, navigating access and importantly, understanding the nature of information of creation and (re)creation. Significantly the study also demonstrates that mastery of the information does not appear to rest on individual agency, but is, in its early stages, predicated on collectivising information, or drawing together pieces of the information jigsaw (in terms of content knowledge and knowledge about operationalising information skills) in order to build resilience that comes from uncertainty $[63,66]$. This emphasises the importance of understanding information literacy practices holistically, and of recognising that collective nature of this practice operates at both an ontological level (where people engage with the nature of knowledge) and at an epistemological level, where ways of knowing are practised. It also further highlights the limitations of traditional information literacy research, which often neglect to take these collective practices into account [67].

\section{Discussion}

One of the primary goals of the recently filed ACRL Framework's architects was to introduce "a richer, more complex set of core ideas" to librarian educational practice [3]. While this approach provides a much needed and improved update to information literacy education within the United States, the alignment with constructivist conceptual understandings means that the Framework overlooks significant recent research that positions information literacy as a complex sociocultural practice that is shaped through the negotiated meaning making of a community $[5,6]$. The Framework's inherent focus on the individual, or "solitary mastery of the existing system" [68] remains problematic when recent scholarship demonstrates that information literacy is social and dialogic, shaped through the negotiated meaning making and discourses that are constructed around activities [1, p.32]. Similarly, the overwhelming emphasis within the Framework on library and academic concepts could be seen as short sighted when the same research demonstrates that information literacy is not just limited to bibliographic markers [1] and that higher education continues to encompass a number of non-traditional educational opportunities, for example, service learning, internships or study abroad. 
Furthermore, in attaching the Framework to what several authors have termed non-methodologically sound threshold concepts $[52,53,69]$, information literacy continues to be framed in 'ideal' terms and through librarian 'expert' practice rather than as emerging from and within a community. These ideas position information literacy as discovered [53] rather than as emerging through the negotiation of complex, collective practices. They also centre our understandings on librarian conceptions of what students 'struggle' with rather than the nature of information literacy within a specific context [52]. Perhaps it is the confusing definition of knowledge practices, however, that sums up the limitations in this view of information literacy. Seen as representing pseudo standards [70], the use of the term 'knowledge practices' can be critiqued most generally both for suggesting that there is shared understanding and agreement about what constitutes knowledge as well as for failing to acknowledge what or whose knowledge is being privileged. More specifically, however, in positioning knowledge practices as activities that emerge from the development of core or disciplinary knowledge, the Framework misrepresents both the purpose of information activities as well as practice theory itself, which sees activities as facilitating a knowing of a setting and emerging from and being enacted through practices that afford information experiences. These ideas are problematic because they ignore the shaping of information literacy practice, including the bodily and emotional aspects of participation and meaning making that are inherent within the production and the reproduction of identities and performances [1, p.25]. They also impose normative barriers between the student and information literacy practice as well as the range of contexts they will encounter, meaning that students risk leaving the preparatory setting of higher education as unprepared, or without the information literacy competencies that would allow them to remain open to the social, embodied or material affordances that support transition within new contexts.

In juxtaposing this example of refugee health information practices with some of the more problematic aspects of both the behaviourist and the constructivist approach to information literacy within intercultural settings, it is clear that the sociocultural lens provides a far more inclusive way to consider the complexity of newcomer experiences within today's intercultural information environments. At the same time, it is clear that as an approach that is still emerging within the field of information literacy, a number of interesting questions and areas of research remain. An important and underdeveloped area of focus (in both information literacy and information behaviour research) centres upon the academic sphere, and the nature of a sociocultural approach to information literacy within intercultural scholarly settings. To this end, one of the authors (Hicks) has started to explore how language students develop and construct understandings of information literacy practice as they engage in work or study abroad as part of their undergraduate degree [71]. By viewing student information experiences through a sociocultural lens, this study positions residence abroad as an information problem, and information literacy as mediating between language, thought and action to facilitate learner subjectivity in relationship to new cultural contexts. Aiming to expand conversations about the nature and values that are inherent within traditional conceptions of information literacy, this research will also problematise the role of information literacy within a globally focused system of higher education by providing a comparative perspective to existing research. Another area of research focus centres on the classroom or how teacher-librarians can scaffold sociocultural approaches to information literacy, especially since the idea of behavioural Standards would be anachronistic within this new approach. Still in its infancy, research into the educational implications of this research further explore how the use of a sociocultural lens can move beyond scholarly understandings of information literacy to engage with librarian professional practice within academic intercultural contexts $[72,73]$.

The sociocultural approach also raises a number of questions about the nature of transition, or adjustment within a setting. These ideas, which demonstrate the richness and complexity of the sociocultural approach to information literacy, will also be explored in Hicks' ongoing research into language student information literacy practices. Transition has traditionally referred to a passage from one life phase, place or situation to another [74, p.2], but it can also be used to allude to change on a broader sociocultural level, or an individual's development through participation in cultural and community activities [75]. These ideas mean that when we centre information literacy on the student's development of intersubjective or shared understandings of practice [1] rather than the navigation of institutional norms, we position transition at the heart of information landscapes and our experiences within them. More specifically, the idea of transitory information literacy practices, which should not be confused with the concept of transliteracy or the ability to interact across platforms, continues to be particularly important in relation to the experience of people whose knowledge base has become fragmented and disrupted as part of a transition process. As the example of refugee health information practices demonstrates [63], the role of 'others' and social networks are central to the collective coping and resilience building of people in transition. The potential for mis-information further highlights how issues related to power relationships as well as how judgments about the veracity of local or nuanced or informal knowledges should be located at the heart of considerations about transition, as well as incorporated into information literacy education. Questions of transition may also help us to think more broadly about the way we learn new tasks, which has tended to 
focus on the notion of transfer and, more recently, liminality. If, however, information literacy is site-specific and learning is a complex developmental process, the concept of transition may provide an alternative way to think about being, becoming and the development of knowing within information literacy practice.

\section{Conclusion}

Recognising that the ability to adjust to new cultural contexts is becoming increasingly important within many societies today, this paper set out to provide a holistic reflection on the nature of information literacy within intercultural settings. In exploring literature in the area, though, it is apparent that while the problem-deficit stance of information literacy standards research is troublesome, the isolation or individual, rather than community based nature of alternative constructivist frameworks presents a limited view of information literacy. In contrast, research that views information literacy through a sociocultural lens centres upon the emergence of practice and the reconciliation of information landscapes. This approach raises a number of questions that broaden and expand research beyond the measurement of competencies to situate information literacy practices at the heart of social life.

\section{Funding}

This research received no specific grant from any funding agency in the public, commercial or not-for-profit sectors.

\section{References}

[1] Lloyd A. Information literacy landscapes: information literacy in education, workplace and everyday contexts. Oxford, UK: Chandos, 2010.

[2] Association of College and Research Libraries (ACRL). Information Literacy Competency Standards for Higher Education, www.ala.org/ala/acrl/acrlstandards/standards.pdf (2000, consulted July 2015)

[3] Association of College and Research Libraries (ACRL). Framework for Information Literacy for Higher Education, http://www.ala.org/acrl/standards/ilframework (2015, consulted July 2015)

[4] Harris BR. Communities as necessity in information literacy development: challenging the standards. The Journal of Academic Librarianship 2008; 34(3): 248-255.

[5] Lloyd A. Information literacy: different contexts, different concepts, different truths? Journal of Librarianship and Information Science 2005; 37(2): 82-88.

[6] Tuominen K, Savolainen R and Talja S. Information Literacy as a sociotechnical practice. Library Quarterly 2005; 75(3): 329345.

[7] Baldwin JR and Hunt SK. Information-Seeking Behavior in Intercultural and Intergroup Communication. Human Communication Research 2002; 28(2): 272-286.

[8] Association of American Colleges and Universities (AACU). Information Literacy VALUE Rubric, http://www.aacu.org/value/rubrics/information-literacy (2013, consulted July 2015)

[9] Australian and New Zealand Information Literacy Framework (ANZIL). Australian and New Zealand Information Literacy Framework principles, standards and practice, http://www.caul.edu.au/content/upload/files/infoliteracy/InfoLiteracyFramework.pdf (2004, consulted July 2015)

[10] Addison C and Meyers E. Perspectives on information literacy: a framework for conceptual understanding. Information Research 2013; 18(3): 1-13.

[11] Eisenberg M and Berkowitz RE. Information problem-solving: the big six skills approach to library \& information skills instruction. Norwood, N.J: Ablex Pub. Corp, 1990.

[12] Doyle C. Information literacy in an information society: a concept for the information age. Syracuse, NY: Information Resources Publications, 1994.

[13] Markless S and Streatfield D. Three decades of information literacy: redefining the parameters. In: Andretta S. (ed) Change and challenge: information literacy for the twenty-first century. Adelaide: Auslib Press, 2007, pp. 15-36.

[14] Connell V. Getting to know the neighbors : library support for study abroad programs. Library Philosophy and Practice 2009; $1-13$.

[15] Giullian J. Slavic folklore, the library, and the web: a case study of subject-specific collaborative information literacy at the University of Kansas. Slavic \& East European Information Resources 2009; 10(2-3): 200-220.

[16] Luly S and Lenz H. Language in context : A model of language oriented library instruction. Journal of Academic Librarianship 2015; 41(2): 140-148.

[17] White A, Ye Y and Guccione M. Study abroad students: designing library services to meet their needs. Journal of Library Administration 2009; 49(1-2): 187-196.

[18] Stevens C and Campbell P. Collaborating to connect global citizenship, information literacy, and lifelong learning in the global studies classroom. Reference Services Review 2006; 34(4): 536-556. 
[19] Whitehurst A. Information literacy and global readiness: library involvement can make a world of difference. Behavioral \& Social Sciences Librarian 2010; 29(3): 207-232.

[20] Morrison R. Culturally-relevant information literacy: a case study. PhD Thesis, National-Louis University, USA, 2009.

[21] Street B. What's "new" in New Literacy Studies? Critical approaches to literacy in theory and practice. Current Issues in Comparative Education 2003; 5(2): 77-91.

[22] Volet S and Jones C. Cultural transitions in higher education: Individual adaptation, transformation and engagement. In: S Karabenick and T Urdan (eds) Transitions across schools and cultures. Bingley: Emerald, 2012, pp.241-284.

[23] Ryan A \& Tilbury D. Flexible pedagogies: new pedagogical ideas. The Higher Education Academy, 2013.

[24] Montgomery C and McDowell L. Social networks and the international student experience: An international community of practice? Journal of Studies in International Education 2009; 13(4): 455-466.

[25] Lillis T and Scott M. Defining academic literacies research: issues of epistemology, ideology and strategy. Journal of Applied Linguistics 2007; 4(1): 5-32.

[26] O'Connor LG. Librarians' professional struggles in the information age: a critical analysis of information literacy. PhD Thesis, Kent State University, USA, 2006.

[27] Hudson D. Unpacking "information inequality": toward a critical discourse of global justice in library and information science. Canadian Journal of Information and Library Science 2012; 36(3): 69-87.

[28] Pilerot $\mathrm{O}$ and Lindberg J. The concept of information literacy in policy-making texts: an imperialistic project? Library Trends 2011; 60(2): 338-360.

[29] Martin CK, Maxey-Harris C, Graybill JO and Rodacker-Borgens EK. Closing the gap: investigating the search skills of international and US students: an exploratory study. Library Philosophy and Practice 2009; 1-17.

[30] Chen Y-H and Van Ullen MK. Helping international students succeed academically through research process and plagiarism workshops. College and Research Libraries 2011; 72(3): 209-235.

[31] Lewis M. Library orientation for Asian college students. College and Research Libraries 1969; 30(3): 267-272.

[32] Bilal D. International students' acquisition of library research skills: Relationship with their English language proficiency. Reference Librarian 1989; 10(24): 129-145.

[33] Morrissey R and Given L. International students and the academic library: A case study. Canadian Journal of Information and Library Science 2006; 30(3-4): 221-239.

[34] Daniel E, Lloyd R, Martin D, Rao A and Sloan L. Ethnicity, acculturation, and plagiarism: A criterion study of unethical academic conduct. Human Organization 2011; 70(1): 88-96.

[35] Sundin O. Negotiations on information seeking expertise : A study of web- based tutorials for information literacy. Journal of Documentation 2008; 64(1): 24-44.

[36] Addison C and Meyers E. Perspectives on information literacy: a framework for conceptual understanding. Information Research 2014; 18(3): 1-14.

[37] Swanson T. The IL standards and the IL framework cannot co-exist. Tame The Web, http://tametheweb.com/2015/01/12/the-ilstandards-and-il-framework-cannot-co-exist-by-ttw-contributor-troy-swanson/ (2015, consulted July 2015)

[38] SCONUL. Seven Pillars of Information Literacy, http://www.sconul.ac.uk/sites/default/files/documents/coremodel.pdf (2011, consulted July 2015)

[39] Coonan E and Secker J. A New Curriculum for Information Literacy (ANCIL), https://newcurriculum.wordpress.com/ (2011, consulted July 2015)

[40] Bordonaro K. Language learning in the library: An exploratory study of ESL students. Journal of Academic Librarianship 2006; 32(5): 518-526.

[41] Bordonaro K. Is library database searching a language learning activity? College and Research Libraries 2010; 71(3): 273284.

[42] Han J. Information literacy challenges for Chinese PhD students in Australia: a biographical study. Journal of Information Literacy 2012; 6(1): 3-17.

[43] Hughes H. Actions and reactions: Exploring international students' use of online information resources. Australian Academic \& Research Libraries 2005; 36(4): 169-179.

[44] Hughes H. International students' experiences of university libraries and librarians. Australian Academic \& Research Libraries 2010; 41(2): 77-89.

[45] Hughes H. International students using online information resources to learn: complex experience and learning needs. Journal of Further and Higher Education 2013; 37(1): 126-146.

[46] Johnston N. Understanding the information literacy experiences of EFL (English as a Foreign Language) students. PhD Thesis, Queensland University of Technology, Australia, 2014.

[47] Talja S, Tuominen K and Savolainen R. "Isms" in information science: constructivism, collectivism and constructionism. Journal of Documentation 2005; 61(1): 79-101.

[48] Hughes H. Researching the experience of international students. In: Danaher PA, Macpherson C, Nouwens F and Orr D (eds) 3rd International Lifelong Learning Conference: Whose responsibility and what is your contribution? Yeppoon, Queensland, 2004. 
[49] Hughes $\mathrm{H}$ and Bruce C. Cultural diversity and educational inclusivity: International students' use of online information. International Journal of Learning 2006; 12(9): 33-40.

[50] Bruce C. Informed learning. Chicago: Association of College and Research Libraries, 2008.

[51] Kim J. The birth of academic subalterns: How do foreign students embody the global hegemony of American universities? Journal of Studies in International Education 2011; 16(5): 455-476.

[52] Wilkinson L. The problem with threshold concepts. Sense and reference. https://senseandreference.wordpress.com/2014/06/19/the-problem-with-threshold-concepts/ (2014, consulted July 2015)

[53] Morgan PK. Pausing at the threshold. portal: Libraries and the Academy 2015; 15(1): 183-195.

[54] Meyer J \& Land M. Threshold concepts and troublesome knowledge: Linkages to ways of thinking and practising within the disciplines 2003; 1-16.

[55] Talja S and Lloyd A. Integrating theories of learning, literacies and information practices. In: Lloyd A and Talja S (eds) Practising information literacy; bringing theories of learning, practice and information literacy together. Wagga Wagga, Australia: Centre for Information Studies, 2010, pp.301-330.

[56] Lloyd A. Information literacy as a socially enacted practice: sensitising themes for an emerging perspective of people-inpractice. Journal of Documentation 2012; 68(6), 772-783

[57] Limberg L, Sundin O, Talja, S. Three theoretical perspectives on information literacy. Human IT 2011; 11(2): 93-130.

[58] Lloyd, A. Trapped between a rock and a hard place: What counts as information literacy in the workplace and how is it conceptualized? Library Trends 2011; 60(2): 277-296.

[59] Whitworth, A. Radical information literacy. Oxford: Chandos, 2014.

[60] UNESCO. Beacons of the Information Society: The Alexandria Proclamation on Information Literacy and Lifelong Learning. $\mathrm{http}$ //www.ifla.org/publications/beacons-of-the-information-society-the-alexandria-proclamation-on-information-literacy (2005, consulted November 2015)

[61] Caidi N, Komlodi A, Abrao AL and Martin-Hammond, A. Collectively figuring it out: foreign-trained health professionals and labor market integration. LIBRES: Library and Information Science Research Electronic Journal 2014; 24(2): $118-131$.

[62] Lloyd A, Kennan MA, Thompson KM and Qayyum A. Connecting with new information landscapes: Information literacy practices of refugees. Journal of Documentation 2013, 69(1): 121-144.

[63] Lloyd A. Building information resilience: how do resettling refugees connect with health information in regional landscapesImplications for health literacy. Australian Academic \& Research Libraries 2014; 45(1): 48-66.

[64] Charmaz K. Constructing grounded theory. London: Sage, 2014.

[65] Kao G. Social capital and its relevance to minority and immigrant populations. Sociology of Education 2004; 77(2): 172-83

[66] Lloyd A. Stranger in a strange land: Enabling information resilience in resettlement landscapes. Journal of Documentation 2015; 71(5): 1029-1042.

[67] Harris B. Communities as necessity in information literacy development: challenging the standards. The Journal of Academic Librarianship 2008; 34(3): 248-255.

[68] Beilen I. Beyond the Threshold: Conformity, Resistance, and the ACRL Information Literacy Framework for Higher Education. In the library with the lead pipe. http://www.inthelibrarywiththeleadpipe.org/2015/beyond-the-thresholdconformity-resistance-and-the-aclr-information-literacy-framework-for-higher-education/ (2015, consulted July 2015)

[69] Saracevic T. Information Literacy in the United States: Contemporary Transformations and Controversies. Communications in Computer and Information Science 2014; 492: 19-30

[70] Seale M. Enlightenment, Neoliberalism, and Information Literacy. In: Proceedings of CAPAL15, In Press.

[71] Hicks A. Learning a different language: Information literacy in transition. PhD Thesis, Charles Sturt University, Australia, in process.

[72] Hicks A. Knowledge Societies: Learning for a diverse world. In: Swanson TA and Jagman H (eds) Not just where to click: teaching students how to think about information. Chicago: ACRL, 2015, pp. 217-242.

[73] Hicks A. Drinking on the job: Integrating workplace information literacy into the curriculum. LOEX Quarterly 2015; 41(4): 915.

[74] Schumacher KL, Jones PS and Meleis AI. Helping elderly persons in transition: A framework for research and practice. In: Swanson EA and Tripp-Reimer T (eds) Life transitions in the older adult: Issues for nurses and other health professionals. New York, NY: Springer, 1999, pp. 52-72.

[75] Rogoff, B. The cultural nature of human development. Oxford: Oxford University Press, 2003. 